Resumo

\title{
Efeito agudo do exercício contrarresistência com restrição de fluxo sanguíneo sobre o volume sanguíneo muscular no modo isotônico
}

Tiago Marques Silva Bsci, Cláudia Meirelles PhD

Introdução: 0 exercício com restrição de fluxo sanguíneo (RFS) tem se mostrado eficiente para o treinamento de indivíduos incapazes de realizar exercícios de alta intensidade, tendo, no entanto, resultados similares ou melhores que os de alta intensidade. Vários são os mecanismos estudados para explicar os ganhos nesse tipo de exercício, no entanto, ainda não há respostas fisiológicas claras que expliquem o fenômeno. As respostas hemodinâmicas advindas da RFS em exercícios ainda deixam lacunas na literatura científica.

Objetivo: Analisar as respostas de volume sanguíneo em exercício contrarresistência em cadeira extensora com restrição de fluxo sanguíneo no modo isotônico.

Métodos: Foram estudados 12 voluntários do sexo masculino (idade 18,7 $\pm 0,5$ anos; massa corporal $66,9 \pm 8,0 \mathrm{~kg}$; estatura $174,9 \pm 7,2 \mathrm{~cm}$; \% gordura 9,2 $\pm 3,5$ ) sem experiência em TCR. Antes da coleta foi realizado o protocolo de 1RM para extensão unilateral de joelho bem como aferida, na artéria poplítea, a pressão de oclusão total $(\mathrm{M}=160 \pm 15,8 \mathrm{mmHg})$ para que fosse utilizada a pressão de RFS a $50 \%$ (80 \pm 7,9 mmHg) na execução das séries. 1ํo dia: explicação e assinatura do TCLE; antropometria; aferição das pressões totais e parciais de fluxo sanguíneo findando com a familiarização. $2^{\circ}$ dia: Teste propriamente dito com o seguinte protocolo: 3 séries de 15 repetições; $50 \%$ RFS a 30\% de 1RM com intervalos de 30 segundos entre as séries e 3 minutos ao final. Foi utilizado a análise de variância (ANOVA) 2 x 3, condição x tempo, com medidas repetidas no segundo fator; post-hoc Bonferroni para identificação de possíveis diferenças nas respostas monitoradas durante as séries e os intervalos de recuperação nas condições com e sem RFS.

Resultados: Foi identificado efeito principal do tempo $(p<0,05)$, sem interação significativa entre as condições com e sem restrição de fluxo sanguíneo $(p>0,05)$. Conclusão: De acordo com os resultados encontrados não houve diferença significativa entre as condições com e sem RFS, o que sugere que novos estudos sejam feitos. 